\title{
Detection of bacterial DNA by in situ hybridization in patients with decompensated liver cirrhosis
}

\author{
Shingo Usui ${ }^{1 *}$, Hirotoshi Ebinuma ${ }^{1,2}$, Po-Sung Chu', Nobuhiro Nakamoto ${ }^{1 *}$, Yoshiyuki Yamagishi ${ }^{1,3}$,
} Hidetsugu Saito ${ }^{1,4}$ and Takanori Kanai ${ }^{1}$

\begin{abstract}
Background: Spontaneous bacterial peritonitis (SBP) is often difficult to diagnose because bacteria in ascites cannot be detected accurately by conventional culture. In situ hybridization (ISH) was previously developed for rapid detection of genes from bacteria phagocytized by neutrophils. SBP may develop after bacteria enter into the systemic circulation following bacterial translocation. Therefore, we performed ISH to identify bacteria in blood samples collected from patients with decompensated liver cirrhosis (LC).

Methods: In this retrospective study, peripheral blood samples were collected from 60 patients with decompensated LC, and bacteria were detected by both blood culture and ISH. Moreover, 35 patients underwent paracentesis for diagnosis of SBP.

Results: Eight of 35 patients were diagnosed with SBP by polymorphonuclear neutrophil counts, and one patient was diagnosed with bacterascites. Seven of the nine patients showed positive results for ISH, whereas bacteria were detected in only two cases by blood culture. Thirty-seven of 60 cases (62\%) showed positive results for ISH, whereas only six samples (10\%) were positive by blood culture analysis. Compared with the 23 cases of negative ISH, the 37 cases of positive ISH showed a higher frequency of fever, higher Child-Pugh scores, and lower albumin levels.

Conclusions: Detection of bacteria by ISH suggested that bacterial translocation, which cannot be proven by conventional culture, occurred in these patients, and that ISH could be helpful for the early diagnosis of some types of infection and prevention of SBP in these patients.
\end{abstract}

Keywords: Spontaneous bacterial peritonitis, Bacterial translocation, Liver cirrhosis, In situ hybridization, Blood culture

\section{Background}

Patients with decompensated liver cirrhosis (LC) often suffer from various complications, such as hepatic encephalopathy, jaundice, gastroesophageal varices, and ascites. Spontaneous bacterial peritonitis (SBP), which was first reported by Conn and Fessle in 1971, is associated with a poor prognosis [1-4]. Early diagnosis and antibiotic treatment are necessary for management of SBP $[4,5]$. However, it is difficult to diagnose SBP because

\footnotetext{
* Correspondence: usui@a3.keio.jp; nobuhiro@z2.keio.jp

${ }^{1}$ Division of Gastroenterology and Hepatology, Department of Internal Medicine, Keio University School of Medicine, 35 Shinanomachi, Shinjuku-ku, Tokyo 160-8582, Japan

Full list of author information is available at the end of the article
}

bacteria in ascites or blood cannot be detected accurately by conventional culture in a timely manner. Polymorphonuclear neutrophil (PMN) counts in ascites are useful for diagnosis of SBP, and empirical antibiotic therapy should be started immediately after the diagnosis of SBP without knowledge of the causative bacteria [5].

The use of in situ hybridization (ISH) for detection of genes from bacteria phagocytized by neutrophils in ascites may have applications in the diagnosis of SBP [6]. ISH was developed to detect bacteria rapidly in patients with suspected bacterial infection [7] and can be applied to identify bacterial genes in neutrophils directly under a microscope after collection of blood samples from patients. Enomoto et al. reported that ISH is highly 
sensitive for detection of bacteria in ascites from patients with SBP [6]. Indeed, SBP may develop following bacterial translocation, during which enteric bacteria cross the intestinal epithelial cells, reach mesenteric lymph nodes [8], and enter into the systemic circulation [9]. Therefore, we hypothesized that patients with SBP may already exhibit systemic bacterial inflammation.

Accordingly, in this study, we attempted to detect bacteria in blood samples from patients with decompensated LC by ISH, and evaluated the utility of ISH compared with conventional blood culture in these patients.

\section{Methods}

\section{Patients}

Patients admitted to Keio University Hospital from April 2008 to March 2011 and who underwent ISH were included in this retrospective study. We performed ISH a total of 110 times in 94 patients. Twenty-five cases were patients without liver disease, and 13 cases were patients without cirrhosis. Sixty of 72 patients had ascites and were diagnosed with decompensated LC. Blood samples from 60 patients diagnosed with decompensated LC were simultaneously examined by ISH and blood culture. Moreover, 35 patients with mild or severe ascites underwent paracentesis to diagnose SBP by PMN counts of no less than $250 / \mu \mathrm{L}$ in ascitic samples, and ascitic samples were investigated with the blood samples simultaneously (Fig. 1). This study was approved by the ethics committee of our university hospital.

\section{ISH}

ISH was performed using a commercial kit provided by Fuso Pharmaceuticals (Osaka, Japan). In ISH, the probes used to detect bacterial genomes for Staphylococcus aureus (SA), S. epidermidis (SE), Pseudomonas aeruginosa (PA), Enterococcus faecalis (EF), and a group of enterobacteria (Escherichia coli, Enterobacter cloacae, and Klebsiella pneumoniae [EK]) were previously established [7]. These pathogens are frequent causes of bacterial infections in patients with SBP $[4,10]$.

ISH was performed using blood samples from patients. Briefly, heparinized blood samples from patients were cen-

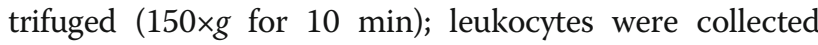
after hemolysis with hypotonic buffer and resuspended in phosphate-buffered saline (PBS) at a concentration of $5 \times 10^{4}$ cells $/ \mu \mathrm{L}$. A sample of the cellular suspension (5$10 \mu \mathrm{L}$ ) was spread onto a glass slide and air-dried. The slide was fixed in Carnoy's solution for $20 \mathrm{~min}$ and permeabilized; bacterial DNA was denatured. Digoxygenin (Dig)-labeled probes and anti-Dig-alkaline phosphatase (ALP) were used for detection. Intracellular Dig-labeled hybridized signals were detected by anti-Dig-ALP. To visualize the signals, color development was achieved using nitro blue tetrazolium (NBT)-5-bromo-4-chloro-3indolyl phosphate (BCIP) as a substrate for ALP. Positive signals in the cell cytoplasm were observed under a microscope. Blue-colored dots in neutrophils, representing phagocytic bacteria, were assumed to represent a positive result.

\section{Blood and ascitic cultures}

All blood and ascitic samples were collected into both aerobic and anaerobic blood culture bottles. Blood and ascitic culture bottles were sent to the reference microbiology laboratory of our hospital for processing. The blood culture system BD Bactec FX (Nippon Becton Dickinson, Tokyo, Japan) was used for the detection of pathogens. Samples were incubated at $37^{\circ} \mathrm{C}$ for 5 days.

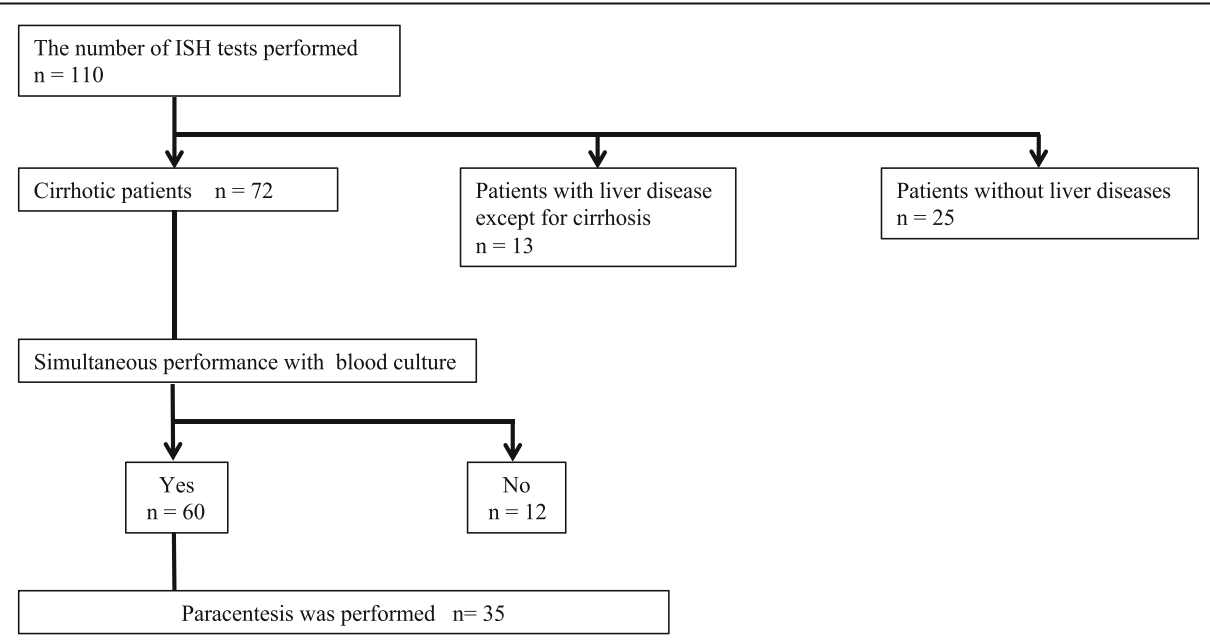

Fig. 1 Algorithm for cases performed by ISH. We performed ISH 110 times for 94 cases. Twenty-five cases were patients without liver diseases, and 13 cases did not exhibit cirrhosis. Twelve of 72 patients with liver cirrhosis were examined with ISH only; thus, 60 samples were included in this study 
Isolates of microorganisms were identified using a Bactec FX system.

\section{Statistical analysis}

Comparisons of the frequencies between the two groups were analyzed by McNemar's tests. Baseline data for patients with LC were statistically evaluated. Variables were expressed as the mean \pm standard deviation (SD), and differences between two groups were evaluated by Student's t-tests, and three groups by ANOVA.

\section{Results}

\section{Patient background}

Table 1 shows the characteristics of the 60 patients included in this study. ISH and conventional blood cultures were performed in 60 patients with ascites out of 72 decompensated LC patients. The median age was 62 years, and the patients were predominantly male (male:female $=35: 25)$. The causes of cirrhosis were hepatitis B virus infection $(n=4)$, hepatitis $C$ virus infection $(n=18)$, alcohol $(n=21)$, and other factors $(n=17)$. All patients had ascites, and their Child-Pugh scores were no less than 8 . The Child-Pugh classifications were $B$ and $C$, and the mean score was $9.97 \pm 1.55$. The median total bilirubin value was $2.85 \mathrm{mg} / \mathrm{dL}$, and the maximum value was $29.2 \mathrm{mg} / \mathrm{dL}$. The mean albumin and creatinine values were $2.41 \pm 0.47 \mathrm{mg} / \mathrm{dL}$ and $1.18 \pm 0.71 \mathrm{~g} / \mathrm{dL}$, respectively. The median Model For

Table 1 Baseline characteristics of patients with cirrhosis who underwent ISH

\begin{tabular}{|c|c|}
\hline & Mean \pm SD or median value (range) \\
\hline Age (years) & $62(29-84)$ \\
\hline Sex (male/female) & $35 / 25$ \\
\hline Etiology (HBV/HCV/alcohol/others) & $4 / 18 / 21 / 17$ \\
\hline Child-Pugh classification (B/C) & $23 / 37$ \\
\hline Child-Pugh score & $9.97 \pm 1.55$ \\
\hline Total bilirubin (mg/dL) & $2.85(0.3-29.2)$ \\
\hline Albumin (g/dL) & $2.41 \pm 0.47$ \\
\hline Prothrombin time (INR) & $1.38(0.97-2.38)$ \\
\hline Creatinine (mg/dL) & $1.18 \pm 0.71$ \\
\hline White blood cell counts $(/ \mu \mathrm{L})$ & $6350(2000-27,800)$ \\
\hline Platelet counts $\left(\times 10^{3} / \mu \mathrm{L}\right)$ & $78.5(20-760)$ \\
\hline C-reactive protein (mg/dL) & $2.42(0.12-15.53)$ \\
\hline MELD score & $15(7-34)$ \\
\hline Esophageal varices (+/-) & $36 / 24$ \\
\hline Hepatocellular carcinoma (+/-) & $19 / 41$ \\
\hline Abdominal pain (+/-) & $4 / 56$ \\
\hline Diabetes mellitus (+/-) & $17 / 43$ \\
\hline
\end{tabular}

Valuables are the mean \pm standard deviations (SDs) or median (range) $\mathrm{HBV}$ : hepatitis B virus, $\mathrm{HCV}$ : hepatitis virus
End-Stage Liver Disease (MELD) score was 15. Patients with diabetes were those who were diagnosed as such by fasting blood glucose or oral glucose tolerance test and treated with insulin or hypoglycemic drugs.

\section{Comparison between ISH and blood cultures in patients undergoing paracentesis}

Eight cases were diagnosed with SBP based on PMN counts. The diagnosis of SBP was based on elevated PMN counts $(\geq 250 / \mu \mathrm{L})$ in 35 cases undergoing paracentesis (Fig. 2). ISH results were positive in six of eight SBP cases, whereas only one case was positive for blood culture. One patient who was positive for ascitic culture was also positive for ISH but negative for blood culture. In seven ascitic culture-negative cases, five were positive for ISH, and one was positive for blood culture. One patient was diagnosed with bacterasites and showed positive results for both ISH and blood culture. Of note, 14 of 27 patients who were not diagnosed with SBP by PMN counts of ascites were positive for ISH, and three out of 14 patients later proved to be positive for blood culture, suggesting that ISH might be useful to diagnose bacterial infection in decompensated LC patients earlier than conventional ways. We did not find any cases who were negative for ISH but positive for ascitic cultures or blood cultures.

\section{Differences in detection rates between ISH and blood culture}

Of the 60 cases who underwent both ISH and blood culture, six were positive for bacteremia by blood culture (10.0\%), whereas 37 were positive by ISH (61.7\%; $p<0.001$; Table 2). The rate of positive detection by ISH was significantly higher than that by blood culture. All positive cases by blood culture were positively detected by ISH, and no cases were negative for ISH but positive for blood culture.

\section{Clinical features and detection of ISH}

Thirty of the 60 patients had fever. Among the patients with fever, 23 cases (76.7\%) were positive for ISH analysis, and six (20.0\%) were positive for blood cultures. Among the patients without fever, 14 cases (46.7\%) were positive for ISH analysis, but none was positive for blood cultures. In $47 \mathrm{C}$-reactive protein (CRP)-positive cases ( $\geq 1 \mathrm{mg} / \mathrm{dL}), 30(63.8 \%)$ and four $(8.5 \%)$ cases were positive for ISH analysis and blood cultures, respectively. The rates of positive results between ISH and blood cultures differed significantly, suggesting that ISH may detect bacteria more sensitively than conventional blood culture (Table 3). Among 24 patients with antibiotic use, oral or intravenous antibiotic treatment was given to 22 patients for confirmed or suspected bacterial infections with unidentified origin. Two patients received an oral 


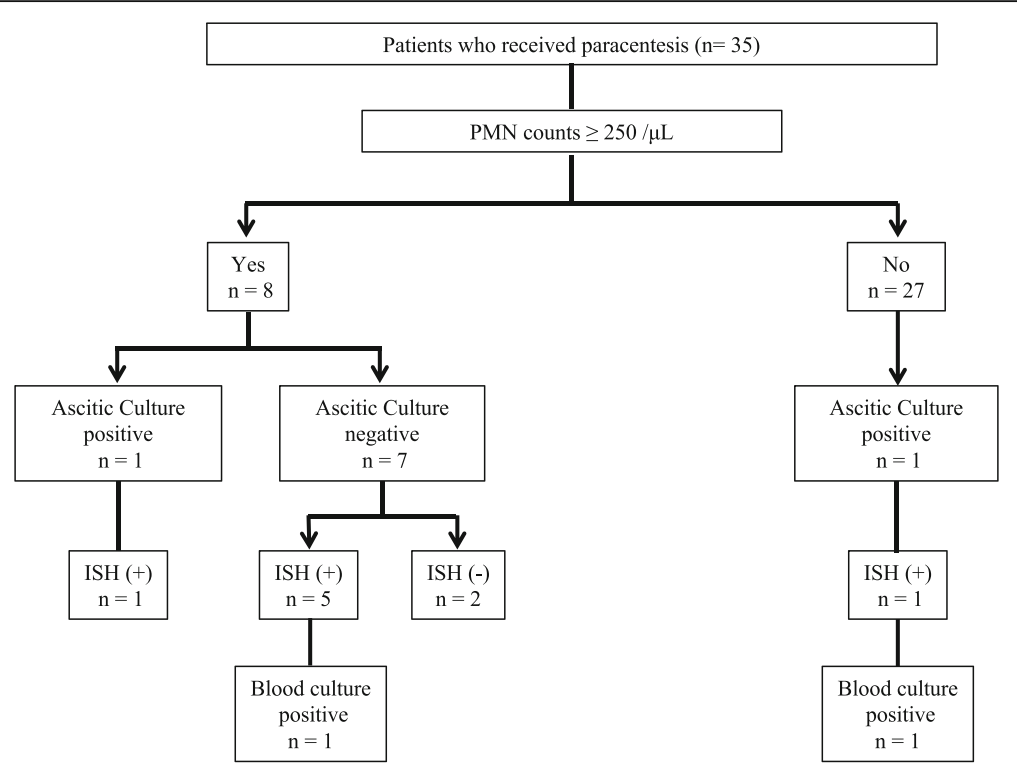

Fig. 2 Algorithm of patients who received paracentesis. Eight of 35 patients were diagnosed with spontaneous bacterial peritonitis (SBP). Six cases of SBP (75.0\%) were positive for bacteremia by ISH, but only one patient (12.5\%) was positively identified by blood bottle culture

aminoglycoside bactericidal antibiotic called kanamycin for prevention of SBP. It is possible that using antibiotics in these patients possibly affected the sensitivity of blood culture.

Moreover, we compared the clinical characteristics between ISH/blood culture positive $(+/+)$, ISH positiveblood culture negative (+/-), and both negative (-/-) patients (Table 4). There were significant differences in the frequency of clinical symptom of fever between the three groups $(p<0.05)$, suggesting that ISH or the combination of ISH and blood culture is useful for the early diagnosis of bacterial infection. Further study in a larger sample size is needed to validate the results.

\section{Detection of bacterial groups by ISH}

Table 5 shows the DNA probes used for detection of bacteria in ISH and the number of positive cases by each probe. The EK probe was positive in almost all cases (81\%). Eight cases showed positive ISH results for the EK probe and another probe simultaneously.

Table 2 Differences in detection rates between blood culture and $\mathrm{ISH}$

\begin{tabular}{lllll}
\hline & & \multicolumn{2}{l}{ Blood culture } & Total \\
\cline { 3 - 4 } & & Positive & Negative & \\
\hline ISH & Positive & $6(10.0 \%)$ & $31(51.7 \%)$ & $37(61.7 \%)$ \\
& Negative & $0(0 \%)$ & $23(38.3 \%)$ & $23(38.3 \%)$ \\
\multirow{2}{*}{ Total } & & $6(10.0 \%)$ & $54(90.0 \%)$ & $60(100 \%)$ \\
\hline
\end{tabular}

\section{Discussion}

In this study, we successfully employed ISH to detect pathogens in the blood from patients with decompensated LC in whom blood culture results were negative for bacterial infection. These findings suggested that bacterial translocation cannot be always detected by conventional blood culture because SBP is known to occur after bacterial translocation, defined as the passage of bacteria from the intestine or colon through the intestinal epithelial cells and entrapment in the mesenteric lymph nodes [8, 11]. After bacterial translocation, bacteria are thought to enter the systemic bloodstream and access ascitic fluid, which exhibits low bactericidal capacity $[9,12-14]$. Bacterial translocation has been demonstrated in some studies in both human and animal models of LC $[15,16]$. However, it is unclear how SBP develops from bacterial translocation because this event cannot be detected easily by conventional blood

Table 3 Positive detection rates by ISH and blood cultures according to clinical manifestations

\begin{tabular}{lllll}
\hline & No & $\begin{array}{l}\text { ISH } \\
\text { positive }\end{array}$ & $\begin{array}{l}\text { Blood culture } \\
\text { Positive }\end{array}$ & $P$ value \\
\hline Total & 60 & $37(61.7 \%)$ & $6(10.0 \%)$ & $<0.001$ \\
Fever & 30 & $23(76.7 \%)$ & $6(20.0 \%)$ & $<0.001$ \\
No fever & 30 & $14(46.7 \%)$ & $0(0.0 \%)$ & - \\
CRP $\geq 1 \mathrm{mg} / \mathrm{dL}$ & 47 & $30(63.8 \%)$ & $4(8.6 \%)$ & $<0.001$ \\
CRP $<1 \mathrm{mg} / \mathrm{dL}$ & 13 & $7(53.8 \%)$ & $2(15.4 \%)$ & 0.0253 \\
Antibiotic use & 24 & $15(62.5 \%)$ & $2(8.3 \%)$ & $<0.001$ \\
\hline Statistical significance &
\end{tabular}


Table 4 Comparison of clinical manifestations among positive (+/+), ISH positive-blood culture negative (+/-), and fully negative (-/-) patients

\begin{tabular}{|c|c|c|c|c|}
\hline ISH/blood culture & $(+/+)$ & $(+/-)$ & $(-/-)$ & $P$ value \\
\hline No. & 6 & 31 & 23 & \\
\hline Fever $(+)$ & $6(100 \%)$ & $17(55 \%)$ & 7 (30\%) & $<0.001$ \\
\hline CRP (mg/dL) & $3.40 \pm 1.44$ & $3.98 \pm 0.63$ & $2.92 \pm 0.75$ & N.S. \\
\hline Child-Pugh score & $11.3 \pm 0.6$ & $10.1 \pm 0.3$ & $9.4 \pm 0.3$ & 0.020 \\
\hline MELD score & $18.0 \pm 2.6$ & $17.4 \pm 1.1$ & $15.6 \pm 1.3$ & N.S. \\
\hline Total bilirubin (mg/dL) & $7.62 \pm 2.97$ & $6.85 \pm 1.30$ & $4.34 \pm 1.51$ & N.S. \\
\hline Albumin (g/dL) & $2.17 \pm 0.19$ & $2.33 \pm 0.08$ & $2.58 \pm 0.10$ & N.S.(0.066) \\
\hline Prothrombin time (INR) & $1.49 \pm 0.11$ & $1.40 \pm 0.05$ & $1.38 \pm 0.06$ & N.S \\
\hline Platelet counts $\left(\times 10^{3} / \mu \mathrm{L}\right)$ & $68.8 \pm 45.2$ & $99.7 \pm 19.9$ & $134.7 \pm 23.1$ & N.S. \\
\hline Diabetes mellitus (+) & $4(67 \%)$ & $9(29 \%)$ & $4(17 \%)$ & 0.049 \\
\hline $\mathrm{HCC}(+)$ & $4(67 \%)$ & $7(23 \%)$ & $8(35 \%)$ & N.S. \\
\hline Esophageal varix (+) & $4(67 \%)$ & $18(58 \%)$ & $14(61 \%)$ & N.S. \\
\hline
\end{tabular}

culture [11]. Such et al. reported that bacterial DNA can be detected simultaneously in blood and ascitic fluid $[17,18]$, using a polymerase chain reaction (PCR)based method. Although this method may provide evidence of the relationship between bacterial translocation and SBP, no studies have compared PCR-based methods with blood culture. Therefore, we hypothesized that ISH could be applied to decompensated LC patients to detect bacteria and may be helpful for selecting patients who may have an infection earlier and determining the proper antibiotic to use if bacteria are present in the systemic bloodstream after bacterial translocation.

ISH was first developed to enable early diagnosis of sepsis within 1 day, using ISH of the bacterial genomes existing in neutrophils after phagocytosis. This method was reported to be four times as sensitive as blood culture for detection of bacteria in patients with sepsis [7]. The other advantages of the ISH method are that it can eliminate potential contamination and is not affected by antibiotic use, as it analyzes pathogens already captured into neutrophils by phagocytosis. Thus, the probability

Table 5 Bacterial strains detected by ISH

\begin{tabular}{lll}
\hline Bacteria & ISH probe & Number of positive cases \\
\hline Escherichia coli & EK & $30(81.1 \%)$ \\
$\begin{array}{l}\text { Enterobacter cloacae } \\
\text { Klebsiella pneumoniae }\end{array}$ & \\
Enterococcus faecalis & EF & $6(16.2 \%)$ \\
Staphylococcus aureus & SA & $5(13.5 \%)$ \\
Pseudomonas aeruginosa & PA & $4(10.8 \%)$ \\
Staphylococcus epidermidis & SE & $0(0.0 \%)$ \\
\hline
\end{tabular}

of false-positive results is low with this procedure. Enomoto et al. developed a new probe mixture, designated a global bacteria (GB) probe, which was capable of detecting all relevant bacterial strains. Using ISH, this probe showed positive results in 10 of 11 SBP cases and negative results in none of 40 non-SBP cases in ascites [6]. Bacteria causing SBP are frequently gram-negative rods, such as Escherichia coli and K. pneumoniae, or can be Streptococcus species [10]. Such et al. studied bacterial DNA to show that Escherichia coli were the most frequently identified bacteria [18]. This is consistent with our results demonstrating that Enterobacteria were frequently detected. Therefore, even five specific probes without the global bacteria probe may be useful for detection of bacteria in patients with decompensated LC. These results suggest that early detection of specific bacteria causing SBP and early therapeutic intervention using appropriate antibiotics are additional advantages of ISH for patients with LC and SBP. However, further studies are needed to confirm this assumption. Additionally, blood cultures beyond ISH tests are thought to be necessary for such patients because bacteria other than the five species probed by ISH may be detected and because drug susceptibility tests cannot be performed by ISH.

Interestingly, in our study, some clinical parameters were related to the results of ISH tests, including the presence of fever and Child-Pugh scores. These results may also be related to the occurrence of bacterial translocation. Cirera et al. detected enteric organisms increasingly from mesenteric lymph nodes in patients with or without cirrhosis according to the Child-Pugh score: $3.4 \%$ in $\mathrm{A}, 8.1 \%$ in $\mathrm{B}$, and $30.8 \%$ in $\mathrm{C}$ [15]. Bacteria in neutrophils were detected in $47 \%$ of patients without 
fever and in 54\% of patients whose CRP levels were below $1 \mathrm{mg} / \mathrm{dL}$ in our study. Surprisingly, bacterial translocation may already be present in asymptomatic patients with LC having ascites. Evans et al. reported that $3.5 \%$ of all outpatients with cirrhosis had SBP, and $1.9 \%$ of these patients had bacterascites [19]. Moreover, several studies have also demonstrated that more severe liver failure is associated with lower CRP levels [20, 21]. Administration of antibiotics may be considered to prevent further deterioration of sepsis or SBP in decompensated LC patients positive for ISH; these patients have no clinical symptoms at this point.

Recent reports have shown that serum albumin functions to maintain oncotic pressure and has immunomodulatory and antioxidant effects. Albumin infusions were found to reduce the incidence of renal failure and mortality in patients with $\operatorname{SBP}[22,23]$. Patients with positive results by ISH had higher Child-Pugh scores and showed a tendency of lower serum albumin levels (Table 4). If hypoalbuminemia indicates immunological deterioration in patients with decompensated LC, patients who are positive for ISH may be required to receive albumin infusions early in addition to antibiotics.

The limitations of this study include the small number of subjects. Obviously, a larger controlled study will be needed to validate the results and confirm the usefulness of ISH.

\section{Conclusions}

In conclusion, bacterial translocation, which often occurs in ascitic patients with LC, cannot be proven by methods such as conventional blood cultures. ISH may be helpful to select patients who are suspected of having an infection, including SBP, and to manage treatment in a timely manner, although additional studies are required.

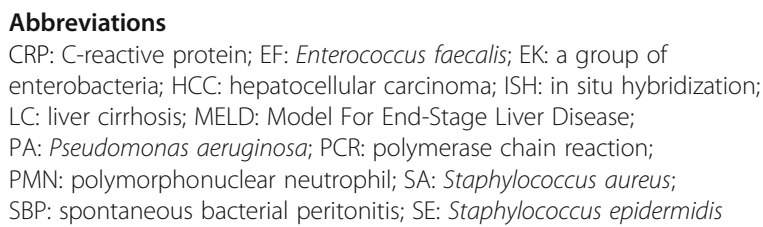

\section{Acknowledgements}

We thank Dr. Yoshio Kobayashi, Ms. Yuko Sumitani, and Mr. Akio Matsuhisa for their helpful and insightful suggestions and technical assistance.

\section{Funding}

This work did not receive any funding.

\section{Availability of data and materials}

The datasets used and/or analyzed during the current study are available from the corresponding author upon request.

\section{Authors' contributions}

SU: study concept and design, acquisition of data, analysis and interpretation of data, statistical analyses, drafting of the manuscript; HE: study concept and design, acquisition of data, analysis and interpretation of data, critical revision of the manuscript for important intellectual content; P-S C: acquisition of data, analysis and interpretation of data, critical revision of the manuscript for important intellectual content; NN: acquisition of data, analysis and interpretation of data, drafting of the manuscript; YY: acquisition of data, analysis and interpretation of data, critical revision of the manuscript for important intellectual content; HS: study concept and design, drafting of the manuscript; TK: study concept and design, critical revision of the manuscript for important intellectual content; All authors read and approved the final manuscript, and agreed to be accountable for all aspects of the works.

\section{Ethics approval and consent to participate}

This study was performed in accordance with the Declaration of Helsinki and ethical guidelines for medical and health research involving human subjects and was approved by the ethics committee of Keio University Hospital (number 20120473). The examinations including ISH conducted in this study were clinically approved, and the ethics committee waived the need to obtain an individual written informed consent, since all data were retrieved retrospectively from the laboratory test information system.

\section{Consent for publication}

Not applicable

\section{Competing interests}

The authors have no financial or nonfinancial competing interests to declare.

\section{Publisher's Note}

Springer Nature remains neutral with regard to jurisdictional claims in published maps and institutional affiliations.

\section{Author details}

'Division of Gastroenterology and Hepatology, Department of Internal Medicine, Keio University School of Medicine, 35 Shinanomachi, Shinjuku-ku, Tokyo 160-8582, Japan. ${ }^{2}$ Department of Internal Medicine, International University of Health and Welfare Mita Hospital, 1-4-3 Mita, Minato-ku, Tokyo 108-8329, Japan. ${ }^{3}$ Department of Internal Medicine, Tokyo Dental College Suidobashi Hospital, 2-9-18 Misakicho, Chiyoda-ku, Tokyo 101-0061, Japan. ${ }^{4}$ Faculty of Pharmacy, Keio University, 1-5-30 Shiba-kohen, Minato-ku, Tokyo 105-8512, Japan.

Received: 30 March 2017 Accepted: 3 October 2017

Published online: 17 October 2017

\section{References}

1. Conn HO, Fessel JM. Spontaneous bacterial peritonitis in cirrhosis: variations on a theme. Medicine (Baltimore). 1971;50:161-97.

2. Garcia-Tsao G. Current management of the complications of cirrhosis and portal hypertension: variceal hemorrhage, ascites, and spontaneous bacterial peritonitis. Gastroenterology. 2001;120:726-48.

3. Solà E, Solé C, Ginès P. Management of uninfected and infected ascites in cirrhosis. Liver Int. 2016;36(Suppl 1):109-15.

4. Dever JB, Sheikh MY. Review article: spontaneous bacterial peritonitisbacteriology, diagnosis, treatment, risk factors and prevention. Aliment Pharmacol Ther. 2015:41:1116-31.

5. European Association for the Study of the Liver. EASL clinical practice guidelines on the management of ascites, spontaneous bacterial peritonitis, and hepatorenal syndrome in cirrhosis. J Hepatol. 2010;53:397-417.

6. Enomoto $\mathrm{H}$, Inoue $\mathrm{S}$, Matsuhisa A, Aizawa N, Imanishi $\mathrm{H}$, Saito M, et al. Development of a new in situ hybridization method for the detection of global bacterial DNA to provide early evidence of a bacterial infection in spontaneous bacterial peritonitis. J Hepatol. 2012;56:85-94.

7. Shimada J, Hayashi I, Inamatsu T, Ishida M, Iwai S, Kamidono S, et al. Clinical trial of in-situ hybridization method for the rapid diagnosis of sepsis. J Infect Chemother. 1999:5:21-31.

8. Wiest R, Lawson M, Geuking M. Pathological bacterial translocation in liver cirrhosis. J Hepatol. 2014;60:197-209.

9. Bellot P, Francés $R$, Such J. Pathological bacterial translocation in cirrhosis: pathophysiology, diagnosis and clinical implications. Liver Int. 2013;33(1):31-9.

10. Koulaouzidis A, Bhat S, Saeed AA. Spontaneous bacterial peritonitis. World J Gastroenterol. 2009;15:1042-9. 
11. Wiest R, Garcia-Tsao G. Bacterial translocation (BT) in cirrhosis. Hepatology. 2005:41:422-33.

12. Zapater P, Francés R, González-Navajas JM, de la Hoz MA, Moreu R, Pascual $\mathrm{S}$, et al. Serum and ascitic fluid bacterial DNA: a new independent prognostic factor in noninfected patients with cirrhosis. Hepatology. 2008; 48:1924-31.

13. Suliman MA, Khalil FM, Alkindi SS, Pathare AV, Almadhani AA, Soliman NA. Tumor necrosis factor-a and interleukin-6 in cirrhotic patients with spontaneous bacterial peritonitis. World J Gastrointest Pathophysiol. 2012;3:92-8.

14. Sheer TA, Runyon BA. Spontaneous bacterial peritonitis. Dig Dis. 2005;23:39-46

15. Cirera I, Bauer TM, Navasa M, Vila J, Grande L, Taurá P, et al. Bacterial translocation of enteric organisms in patients with cirrhosis. J Hepatol. 2001;34:32-7.

16. Guarner C, Runyon BA, Young S, Heck M, Sheikh MY. Intestinal bacterial overgrowth and bacterial translocation in cirrhotic rats with ascites. Hepatol. 1997:26:1372-8.

17. Francés R, Zapater P, González-Navajas JM, Muñoz C, Caño R, Moreu R, et al. Bacterial DNA in patients with cirrhosis and noninfected ascites mimics the soluble immune response established in patients with spontaneous bacterial peritonitis. Hepatology. 2008;47:978-85.

18. Such J, Frances R, Munoz C, Zapater P, Casellas JA, Cifuentes A, et al. Detection and identification of bacterial DNA in patients with cirrhosis and culture-negative, nonneutrocytic ascites. Hepatology. 2002;36:135-41.

19. Evans LT, Kim WR, Poterucha JJ, Kamath PS. Spontaneous bacterial peritonitis in asymptomatic outpatients with cirrhotic ascites. Hepatology. 2003;37:897-901.

20. Fernández J, Gustot T. Management of bacterial infections in cirrhosis. J Hepatol. 2012;56(Suppl 1):S1-12.

21. Mackenzie I, Woodhouse J. C-reactive protein concentrations during bacteraemia: a comparison between patients with and without liver dysfunction. Intensive Care Med. 2006;32:1344-51.

22. Garcia-Martinez R, Caraceni P, Bernardi M, Arroyo V, Jalan R. Albumin: pathophysiologic basis of its role in the treatment of cirrhosis and its complications. Hepatology. 2013;58:1836-46.

23. Guevara M, Terra C, Nazar A, Solà E, Fernández J, Pavesi M, et al. Albumin for bacterial infections other than spontaneous bacterial peritonitis in cirrhosis. A randomized, controlled study. J Hepatol. 2012;57:759-65.

\section{Submit your next manuscript to BioMed Central and we will help you at every step:}

- We accept pre-submission inquiries

- Our selector tool helps you to find the most relevant journal

- We provide round the clock customer support

- Convenient online submission

- Thorough peer review

- Inclusion in PubMed and all major indexing services

- Maximum visibility for your research

Submit your manuscript at www.biomedcentral.com/submit

) Biomed Central 